\title{
Binary reversals in primary progressive aphasia
}

Jason D Warren, Chris J Hardy, Phillip D Fletcher, Charles R Marshall, Camilla N Clark, Jonathan D Rohrer, Martin N Rossor

Dementia Research Centre, UCL Institute of Neurology

University College London, London, United Kingdom

Correspondence: Prof. Jason Warren

Dementia Research Centre

UCL Institute of Neurology

University College London

London WC1N 3BG

Email: jason.warren@ucl.ac.uk

Tel: +44 [0]2034484773

Fax: +44 [0]203 4483104

Running title: Binary reversals in progressive aphasia

Key words: $\quad$ Speech errors; progressive aphasia; lemma; yes; no

Word count: Main text 962 
The words 'yes' and 'no' have long exercised grammarians and language scientists. Despite the fundamental role they play in everyday communication there is surprisingly little uniformity in their usage across languages (the Romans, for instance, seem to have managed without them) and as parts of speech they resist straightforward classification. Their apparent simplicity belies great linguistic subtlety (Critchley, 1970; Schulz, 2015). Indeed it has been argued that they should be regarded as sentences in their own right (Jespersen, 1922).

We have noticed that a number of our patients with progressive aphasia have a peculiar difficulty using 'yes' and 'no' and other binary word pairs in everyday conversation. When required to select between binary alternatives (typically, a question requiring a 'yes' or 'no' response) the patient will often produce one or two false responses, then self-correct, sometimes with evident embarrassment. This phenomenon is perplexing to the patients and their caregivers alike; so striking is the tendency in some cases that patients' caregivers have likened their speech to that of Jim Trott, the character who notoriously reverses 'yes' and 'no' in the popular British television show The Vicar of Dibley. Reversals are not limited to 'yes/no', but may affect a variety of high-frequency verbal binary pairs: examples we have recorded include 'he/she', 'lovely/dreadful', ‘quickly/slowly', 'good morning/afternoon', 'man/woman', 'knife/fork'. Nor are reversals restricted to speech: patients may make similar errors in selecting alternatives when writing and one of our patients following the onset of mutism regularly reversed a nonverbal communicative gesture (thumb up /down). Illustrative examples of the phenomenon in two cases are presented with background neuropsychological data in Table 1; both these patients fulfilled current consensus criteria for progressive nonfluent aphasia (Gorno-Tempini et al., 2011) with supportive brain MRI showing peri-Sylvian cortical atrophy, more marked in the left cerebral hemisphere.

Reversals of 'yes' and 'no' have been noted occasionally in association with stroke aphasia; though the true frequency of binary reversals in this context is not clear, Critchley (1970) noted that 'The aphasic may not always apply [these words] as he would wish. Thus he may 
say 'no' when he means to say 'yes'; or vice versa... he corrects himself... if he can...or he may register distress and exasperation.' Our clinical impression is that binary reversals occur commonly in association with progressive nonfluent aphasia (at least $50 \%$ of cases, based on a retrospective review of our cohort) but may be less common in other progressive aphasia syndromes. In several patients presenting with progressive speech apraxia, binary reversals had been noted early in the course of the illness but their significance had not been appreciated and the patient had been diagnosed with a functional speech disorder. A survey of the published literature suggests that a similar phenomenon has been encountered previously in cases of progressive nonfluent aphasia (Caso et al., 2013; Burrell et al., 2016). However, it has not been emphasised as a feature of the syndrome and has received little attention. Patients with progressive nonfluent aphasia and speech automatisms involving 'yes' and 'no' have also been described (Ghika et al. 1996; Code et al., 2009), though it is not clear whether those cases were associated with production of reversed alternatives, as in our cases; moreover, in our patients the phenomenon has been noted in the absence of other verbal stereotypies. 'Yes/no' reversals were identified as a common association of corticobasal degeneration in one previous series (Frattali et al., 2003) and were also documented in patients with other neurodegenerative and non-degenerative (vascular) pathologies in that series; the finding was interpreted as a nonspecific consequence of impaired front-subcortical inhibitory control processes rather than a feature of aphasia per se. At least in our patients with progressive aphasia, it is not clear to what extent their very prominent binary reversals are accompanied by the more pervasive speech monitoring errors described in other dementia syndromes (McNamara et al., 1992) or more general behavioural disinhibition or response suppression. However, the phenomenon is somewhat reminiscent of the 'motor recklessness' that often accompanies atypical parkinsonism, whereby the patient seems impelled to launch into walking despite clearly impaired postural control: in the verbal analogy, a context-inappropriate motor output (the reversal) is launched rapidly despite clearly impaired speech production control. 
While the cognitive mechanism of binary reversals remains unresolved, we argue for a reappraisal of this phenomenon and its potential relevance to the pathophysiology and diagnosis of progressive nonfluent aphasia and perhaps neurodegenerative language disturbances more generally. Our experience suggests that the phenomenon may emerge early in the course and may lead other, canonical language symptoms or behavioural changes. Any explanation should acknowledge that reversals are not restricted to 'yes/no', or even to speech. We speculate that the relevant deficit of language output may occur at the stage of lemma selection. This process that has attracted considerable neurolinguistic interest and controversy (Roelofs et al., 1998) but it appears to be critical in switching between verbal alternatives during language output (Declerck and Philipp, 2015) and has been implicated as a cognitive locus in progressive nonfluent aphasia (Mack et al., 2015). In line with this, the neuroanatomical evidence would predict a substrate for binary reversals in dominant hemispheric fronto-subcortical circuitry (Frattali et al., 2003; Mack et al., 2015). We propose that, as the damaged language network becomes activated during message assembly, closely related alternative lemmas may be pre-potently activated together and a 'leaky’ neural selection algorithm might then allow the incorrect alternative to enter the output message. This idea could be tested by systematically varying the relatedness of verbal response alternatives and examining the effect on patients' language output (Warren et al., 2003), as indexed by error rate or reaction time. More detailed analysis of the reversals produced by patients with progressive aphasia might illuminate the cognitive significance of the polarities inherent in much verbal communication. 


\section{Acknowledgements}

The Dementia Research Centre is supported by Alzheimer's Research UK, the Brain Research Trust and the Wolfson Foundation. This work was funded by the Wellcome Trust, the UK Medical Research Council and the NIHR Queen Square Dementia Biomedical Research Unit. CJH holds an MRC PhD Studentship. PDF was supported by an MRC Research Training Fellowship. CRM is supported by a Leonard Wolfson Foundation PhD Fellowship. CNC is supported by the National Brain Appeal - Frontotemporal Dementia Research Fund. JDR is an MRC Clinician Scientist. MNR is a NIHR Senior Investigator.

JDW was supported by a Wellcome Trust Senior Clinical Fellowship (Grant No 091673/Z/10/Z). 


\section{References}

Burrell JR, Forrest S, Bak TH, Hodges JR, Halliday GM, Kril JJ. Expanding the phenotypic associations of globular glial tau subtypes. Alz Dem Diag Ass Dis Mon 2016: 1-8.

Caso F, Gesierich B, Henry M, Sidhu M, LaMarre A, Babiak M, Miller BL, Rabinovici GD, Huang EJ, Magnani G, Filippi M, Comi G, Seeley WW, Gorno-Tempini ML. Nonfluent/agrammatic PPA with in-vivo cortical amyloidosis and Pick's disease pathology. Behav Neurol 2013; 26: 95-106.

Code C, Tree JJ, Dawe K. Opportunities to say 'yes': Rare speech automatisms in a case of progressive nonfluent aphasia and apraxia, Neurocase 2009; 15:6, 445-458.

Critchley M. The city of yes, and the city of no. In: Aphasiology and other aspects of language, Edward Arnold: London, 1970.

Declerck M, Philipp AM. A review of control processes and their locus in language switching. Psychon Bull Rev 2015; 22:1630-1645.

Frattali C, Duffy JR, Litvan I, Patsalides AD, Grafman J. Yes/no reversals as neurobehavioral sequela: a disorder of language, praxis, or inhibitory control? Eur J Neurol 2003; 10: 103-106.

Ghika J, Bogousslavsky J, Ghika-Schmid F, Regli F. 'Echoing approval': a new speech disorder. J Neurol 1996; 243: 633-637

Gorno-Tempini ML, Hillis AE, Weintraub S, Kertesz A, Mendez M, Cappa SF, Ogar JM, Rohrer JD, Black S, Boeve BF, Manes F, Dronkers NF, Vandenberghe R, Rascovsky K, Patterson K, Miller BL, Knopman DS, Hodges JR, Mesulam MM, Grossman M. Classification of primary progressive aphasia and its variants. Neurology. 2011; 76: 1006-14.

Jespersen O. Language: Its Nature, Development and Origin. New York: W.W. Norton \& Co, 1922.

Mack JE, Chandler SD, Meltzer-Asscher A, Rogalski E, Weintraub S, Mesulam MM, Thompson CK. What do pauses in narrative production reveal about the nature of word retrieval deficits in PPA? Neuropsychologia 2015; 77: 211-222.

McNamara P, Obler LK, Au R, Durso R, Albert ML. Speech monitoring skills in Alzheimer's disease, Parkinson's disease, and normal aging. Brain Lang. 1992; 42: 38-51.

Roelofs A, Meyer AM, Levelt WJM. A case for the lemma/lexeme distinction in models of speaking: comment on Caramazza and Miozzo (1997). Cognition 1998; 69: 219-230.

Schulz K. What part of 'No, totally' don't you understand? The New Yorker, April 7, 2015.

Warren JD, Warren JE, Fox NC, Warrington EK. Nothing to say, something to sing: primary progressive dynamic aphasia. Neurocase. 2003; 9: 140-55. 
Table 1. Two illustrative cases with binary reversals

\begin{tabular}{|c|c|c|}
\hline Characteristics & CASE 1 & CASE 2 \\
\hline Report of reversals & $\begin{array}{l}\text { I say 'Iovely' all the time. I } \\
\text { mean 'dreadful' and I say } \\
\text { 'lovely' all the time to people. } \\
\text { When I mean 'Good } \\
\text { afternoon', I say 'good } \\
\text { morning'; I think 'good } \\
\text { morning' all the time so it's } \\
\text { hard. I say 'bon jour' and I } \\
\text { can't say 'au revoir' now. }\end{array}$ & $\begin{array}{l}\text { [He's] a little bit like the chap on the } \\
\text { Vicar of Dibley...'no no no no yes'. } \\
\text { Sometimes he seems to say yes or } \\
\text { no quite quickly in the conversation } \\
\text { as if he's trying to gain some time } \\
\text {...[and] black's white. He told me } \\
\text { that he'd met somebody in town and } \\
\text { he was trying to describe this person } \\
\text { and said they went to church and in } \\
\text { the end I found it was a man not a } \\
\text { woman but l'd been led by him to } \\
\text { believe it was a woman. }\end{array}$ \\
\hline \multicolumn{3}{|l|}{ General clinical } \\
\hline Age / gender / handedness & $70 / F / R$ & $69 / M / R$ \\
\hline Education (years) & 18 & 14 \\
\hline Symptom duration (years) & 8 & 5 \\
\hline MMSE $(/ 30)$ & 29 & 29 \\
\hline \multicolumn{3}{|l|}{ General cognitive } \\
\hline \multicolumn{3}{|l|}{ Executive } \\
\hline Trails A (sec) & 62 & 65 \\
\hline Trails B (sec) & $>300$ & 249 \\
\hline $\begin{array}{l}\text { Stroop: } \\
\text { colour naming (sec) }\end{array}$ & 58 & $N / A$ \\
\hline word reading (sec) & 53 & $\mathrm{~N} / \mathrm{A}$ \\
\hline response inhibition (sec) & 89 & $\mathrm{~N} / \mathrm{A}$ \\
\hline \multicolumn{3}{|l|}{ Episodic memory } \\
\hline Recognition Memory Test: Faces (/50) & 44 & $\mathrm{~N} / \mathrm{A}$ \\
\hline Camden Pictorial Memory (/30) & $\mathrm{N} / \mathrm{A}$ & 30 \\
\hline \multicolumn{3}{|l|}{ Language } \\
\hline Graded Naming Test & 18 & 19 \\
\hline Synonyms: concrete (/25) & 24 & 21 \\
\hline Synonyms: abstract (/25) & 21 & 16 \\
\hline Repetition polysyllabic words $(/ 45)^{a}$ & 43 & 43 \\
\hline PALPA55 $(/ 24)^{b}$ & 20 & $\mathrm{~N} / \mathrm{A}$ \\
\hline Test for Reception of Grammar $(/ 19)^{c}$ & $\mathrm{~N} / \mathrm{A}$ & 15 \\
\hline \multicolumn{3}{|l|}{ Perception } \\
\hline VOSP (/20) & 17 & 17 \\
\hline
\end{tabular}

Both patients had a clinical syndromic diagnosis of progressive nonfluent aphasia. Verbatim examples of reversals are from the patient in Case 1 and from the primary caregiver in Case 2 ('yes/no' reversals were prominent in both cases). Bold signifies an abnormal score $\left(<10^{\text {th }}\right.$ percentile based on published norms unless otherwise defined); a, healthy native speakers are assumed to be at ceiling on this test; b, lowest score 22 in an historical cohort of 10 healthy age- and educationmatched individuals; c, lowest score 16 in an historical cohort of 16 healthy individuals aged 50-83; MMSE, Mini-Mental State Examination score; N/A, not available; PALPA, Psycholinguistic Assessments of Language Processing in Aphasia; sec, seconds; VOSP, Visual Object and Space Perception battery 